\title{
Towards dynamic contract extension in supplier development
}

\author{
Karl Worthmann ${ }^{1} \cdot$ Michael Proch $^{2} \cdot$ Philipp Braun $^{3} \cdot$ Jörg Schlüchtermann ${ }^{2}$. \\ Jürgen Pannek ${ }^{4}$
}

Received: 4 January 2016/Accepted: 13 July 2016/Published online: 22 July 2016

(c) The Author(s) 2016. This article is published with open access at Springerlink.com

\begin{abstract}
We consider supplier development within a supply chain consisting of a single manufacturer and a single supplier. Because investments in supplier development are usually relationship-specific, safeguard mechanisms against the hazards of partner opportunism have to be installed. Here, formal contracts are considered as the primary measure to safeguard investments. However, formal contracts entail certain risks, e.g., a lack of flexibility, particular in an ambiguous environment. We propose a receding horizon control scheme to mitigate possible contractual drawbacks while significantly enhancing the supplier development process and, thus, to increase the overall
\end{abstract}

This article is part of a focus collection on "Dynamics in Logistics: Digital Technologies and Related Management Methods".

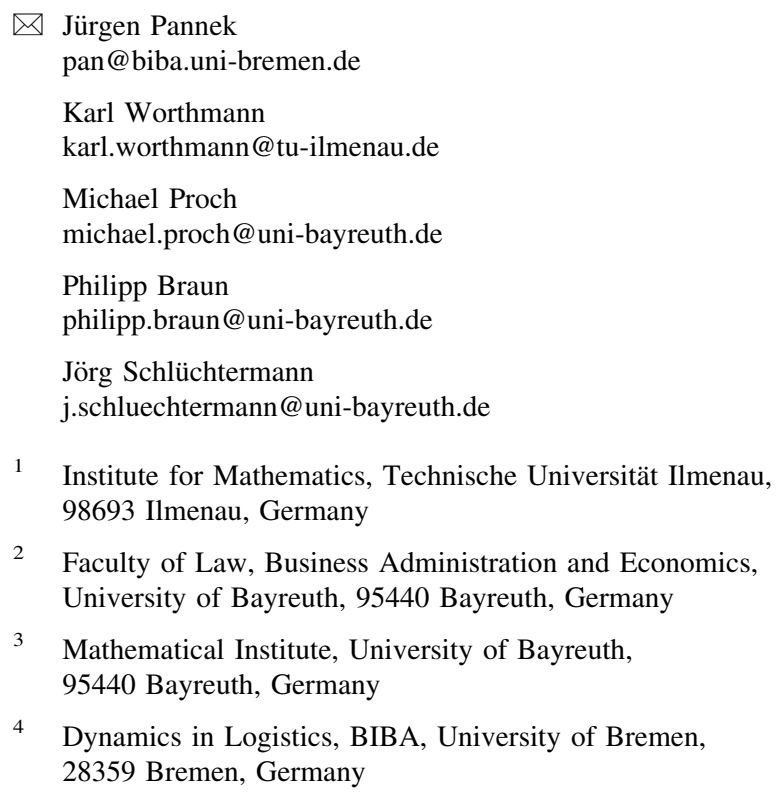

2 Faculty of Law, Business Administration and Economics, University of Bayreuth, 95440 Bayreuth, Germany

3 Mathematical Institute, University of Bayreuth, 95440 Bayreuth, Germany

4 Dynamics in Logistics, BIBA, University of Bremen, 28359 Bremen, Germany

supply chain profit. Our findings are validated by a numerical case study.

Keywords Supply chain management - Supplier development · Optimal control · Receding horizon scheme $\cdot$ Dynamic systems

\section{Introduction}

Since manufacturing firms increasingly focus on their core business activities, an efficient supply chain plays a major role in generating competitive advantages. However, suppliers too often lack the capability to perform adequately. In response, manufacturers across a wide range of industries are implementing supplier development programmes to improve supply chain performance [48]. According to [22, p. 206], supplier development is defined as any effort by a buying firm to improve a supplier's performance and/ or capabilities to meet the manufacturing firm's short-and/ or long-term supply needs.

In accordance with the relational view as proposed by [10], activities of supplier development, in which firms convert general-purpose resources such as money, people skills, or managerial knowledge into relationship-specific resources, represent a rent-generating process. However, relationship-specific resources are difficult or even impossible to redeploy outside the particular business relationship [54]. Thus, firms may see resources committed to supplier development as vulnerable to opportunistic expropriation [51]. Following this line of reasoning, supplier development activities with high levels of asset specificity should be safeguarded against the hazards of partner opportunism [27]. Here, contracts in terms of formalized, legally binding agreements that explicitly specify the 
obligations of each firm, are usually viewed as the primary means of safeguarding, particularly in a dynamically evolving environment $[2,7]$. The drawback of long-term contracts is, as the degree of uncertainty increases, both specifying ex ante all possible contingencies and verifying ex post the performance of the business partner becomes increasingly difficult [54]. Therefore, firms might be reluctant to sign long-term contracts, which potentially diminishes the firms' propensity to invest in supplier development activities and thus impedes the manufacturer's initial strategy to enhance supply chain performance [37].

Given this background, the purpose of our research is to analyse the impact of dynamically extending a contract to mitigate possible contractual hazards. In addition, we seek to answer the following questions: How does the contract period, i.e., planning horizon, affect firms' willingness to commit relationship-specific resources to supplier development? Does receding horizon control offer a straightforward method for dynamically extending the planning horizon, while simultaneously facilitating value generation within supplier development? Further, how should receding horizon control be arranged to optimize supply chain profit?

By answering these questions, the contribution of our paper is threefold. Firstly, we formulate a continuous-time optimal control problem characterizing the supplier development investment decision. We conduct a detailed study, showing that the incentives for firms to participate in supplier development critically depend on the contract period. Secondly, given the fact that long-term contracts entail certain risks, e.g., a lack of flexibility, we utilize receding horizon control and show that the supplier development process can be enhanced by dynamically extending the contract, see [43] for the basic idea of prediction-based control. Based on this result, a one-to-one map is derived linking the contract period to the optimal level of supplier development (collaboration). The insight gained from these considerations allows to either increase the supply chain efficiency or realize the same level of collaboration while being obliged to a shorter contract period. Finally, we present a simple strategy slightly modifying the proposed receding horizon control scheme in order to avoid pathological behaviour of the supply chain. This allows to realize the optimal level of collaboration while avoiding unnecessary transaction costs. The remainder of this paper is structured as follows. Firstly, the related literature is briefly reviewed in Sect. 2 . Then, in Sect. 3 the basic optimal control problem is described. In the subsequent Sect. 4, the dependence of the control policy on the contract period is studied in detail. In Sect. 5, a receding horizon scheme is proposed and analysed before the effectiveness of the developed methodology is demonstrated by means of a numerical case study in Sect. 6 before conclusions are drawn.

\section{Related literature}

The topic of supplier development has received considerable attention from researchers in the past two decades. Previous research has provided good insights into the use of certain activities [47], the antecedents [22], critical success factors [27, 49], and the prevalence of supplier development in practice [24, 41].

Supplier development has been applied in various fields of application [44]. Within the automotive industry, Toyota initially began providing on-site assistance to help suppliers implement the Toyota Production System [39]. Other manufacturers have followed this collaborative approach to develop suppliers' performance and/or capabilities, including Boeing, Chrysler, Daimler, Dell, Ford, General Motors, Honda, Nissan, Siemens, and Volkswagen $[34,38]$. Typically, manufacturing firms use a variety of supplier development activities, e.g., providing performance feedback, training suppliers' personnel, furnishing temporary on-site support to enhance further interaction, providing equipment and tools, or even dedicating capital resources to suppliers $[47,50]$.

Empirical studies support that supplier development is a key factor to attenuate inefficiencies within the supply chain and, thus, strategically contributes to strengthen the manufacturer's competitiveness [28, 40]. Benefits resulting from supplier development include, e.g., improvements in cost efficiency, product quality and/or lead time [17, 25]. However, [23] note that firms' success in supplier development varies. In particular, relationship-specific investments lead, in general, to a more satisfactory outcome. Further, [22] shows that the firms' propensity to participate in supplier development activities is higher if a continuation of the relationship is expected. Here, [49] adds that supplier development is more effective in mature as opposed to initial phases of relationship life cycles.

According to [10], appropriate safeguard mechanisms may influence both transaction costs and the willingness of firms to commit relationship-specific resources to supplier development, a condition that could be an important source of competitive advantage. In the first case, firms achieve an advantage by incurring lower transaction costs to realize a given level of supplier development specificity. In the second case, firms create relational rents by attaining a higher level of asset specificity $[9,46]$. Following this line of reasoning, the firms' ability to align a considerable level of relationship-specific investments with an appropriate safeguard mechanism could enhance efficiency and effectiveness of supplier development activities and thereby should be critical to the success of supplier development.

Scholars usually distinguish between two classes of governance mechanism: the first relies on third-party 
enforcement of agreements, e.g., legal contracts, whereas the second relies on self-enforcing agreements, e.g., relational norms, that make long-term gains from the ongoing relationship exceed potential short-term payoffs from acting opportunistically $[8,45]$. Here, it has been suggested that self-enforcing agreements are a less costly and more effective means of safeguarding relationship-specific investments in comparison with formal contracts [1,35]. Despite the significant methodological and theoretical contributions of these streams of research, empirical evidence shows that formal contracts are still viewed as the primary means of safeguarding against the hazards of partner opportunism, particular in an ambiguous environment $[2,7]$. However, contract research is moving away from a narrow focus on contract structure and its safeguarding function towards a broader focus that also highlights adaptation and coordination as shown in [42]. In [53] it is even suggested that contracts function as relationship management tools.

Nevertheless, the application of formal decision-making models proposed for assisting firms in contract negotiations in order to adequately safeguard relationship-specific investments has received limited attention in the supplier development literature [3]. Without understanding the impact of the contract period on the firms' incentives to commit relationship-specific resources to supplier development, its return will be negligible, perhaps even leading to the premature discontinuation of such collaborative costreduction efforts.

The trend to utilize mathematical models in general and control theory in particular in decision-making within supply chains is clearly visible [18] and [16]. Here, model predictive control (MPC), also termed receding (rolling) horizon control, plays a predominant role due to its ability to deal with nonlinear constrained multi-input multi-output systems on the one hand, see, e.g., [6, 14], and its inherent robustness on the other hand, see [31, 32, 57] for details. Consequently, MPC is a well-established strategy to deal with uncertainties in supply chains, see, e.g., [33, 52] and [19]. In this paper, MPC is first used in supplier development to mitigate possible contractual hazards by dynamical extending the contract, see also our preliminary study [55].

\section{Model description}

We consider a particular supply chain consisting of a single manufacturer $M$ and a single supplier $S$, in which $M$ assembles components from $S$ and sells the final product to the market. We restrict ourselves to the linear price distribution curve $p(d)=a-b d$, which establishes a connection between the production quantity $d$ and the sale price $p$, in order to streamline the upcoming analysis. Here, the coefficients $a>0$ and $b>0$ denote the prohibitive price and the price elasticity of the commodity, respectively. This market condition is comparable with an oligopolistic or monopolistic market structure, in which a firm can increase market demand by lowering the sale price. Similar approaches to specify the price distribution curve have been proposed by $[4,20,27]$.

\subsection{Basic model}

It is supposed that the decision-making process is structured such that $M$ determines the quantity supplied to the market obeying the paradigm of profit maximization. Note that we do not distinguish market demand from the production quantity of the manufacturer because the market price is endogenous to the quantity sold. Moreover, the supplier produces the components to satisfy the demand $d$ and thus does not decide on the production quantity. Because the manufacturer's goal is profit maximization, the production quantity $d$ chosen by $M$ is determined by differentiating

$d \cdot\left(p(d)-c_{M}-c_{S C}\right)$

with respect to $d$ and setting the resulting expression equal to zero, i.e.,

$p(d)-c_{M}-c_{S C}-b d \stackrel{!}{=} 0$,

which yields the optimum production quantity $d^{\star}=$ $\frac{a-c_{M}-c_{S C}}{2 b}$ and the optimal sale price $p\left(d^{\star}\right)=\frac{a+c_{M}+c_{S C}}{2}$. Here, $c_{M}$ and $c_{S C}$ denote the manufacturer's unit production costs and the supply costs per unit charged by $S$, respectively. We further assume that the supplier wants to earn a fixed profit margin $r$. Thus, the supply costs $c_{S C}$ consist of the supplier's fixed profit margin $r$ and the supplier's unit production costs $c_{S}$, i.e., $c_{S C}=r+c_{S}$. This assumption is not completely new: Honda Motor Company, e.g., first learns extensively about a suppliers cost structure and then specifies a target price that combines both the suppliers unit production cost and a percent margin [29]. Similar approaches to specify the supply costs have been proposed by $[4,21,27]$. Summing up, the supply chain profit is given by

$$
\begin{aligned}
J= & J^{M}+J^{S}=\frac{\left(a-c_{M}-c_{S C}\right)^{2}}{4 b}+\frac{a-c_{M}-\left(r+c_{S}\right)}{2 b} r \\
& =\frac{\left(a-c_{M}-c_{S}\right)^{2}-r^{2}}{4 b} .
\end{aligned}
$$

It is supposed that the manufacturer wants to decrease the supplier's unit production costs $c_{S}$ by conducting supplier development projects to increase the market share if that increases the overall profit of the supply chain. To this end, the sustainable effect of supplier development on the 
Table 1 List of parameter

\begin{tabular}{lll}
\hline Symbol & Description & Value \\
\hline$T$ & Contract period & 60 \\
$a$ & Prohibitive price & 200 \\
$b$ & Price elasticity & 0.01 \\
$c_{M}$ & Variable cost per unit $(M)$ & 70 \\
$c_{0}$ & Variable cost per unit $(S)$ & 100 \\
$r$ & Fixed profit margin $(S)$ & 15 \\
$c_{S D}$ & Supplier development cost per unit & 100,000 \\
$\omega$ & Resource availability & 1 \\
$m$ & Learning rate & -0.1 \\
\hline
\end{tabular}

supplier's unit production $\operatorname{costs} c_{S}$ is modelled by $c_{S}(x)=c_{0} x^{m}$, where $c_{0}>0$ denotes the supplier's unit production cost at the outset, $m<0$ characterizes the supplier's learning rate, and $x$ defines the cumulative number of realized supplier development projects. The latter is modelled as a time-dependent function $x:[0, T] \rightarrow \mathbb{R}_{\geq 0}$ governed by the ordinary differential equation

$\dot{x}(t):=\frac{\mathrm{d}}{\mathrm{d} t} x(t)=u(t), \quad x(0)=x_{0}=1$,

with $u \in \mathcal{L}^{\infty}\left(\mathbb{R}_{\geq 0},[0, \omega]\right)$. Here, $u(t)$ describes the number of supplier development projects at time $t$; with capacity bound $\omega>0$ to reflect limited availability of resources in terms of time, manpower, or budget. Similar models of cost reduction through learning have been proposed by [4, 11, 20, 27, 56].

The costs of supplier development are integrated into the proposed model by a penalization term $c_{S D} u(t), c_{S D} \geq 0$. Overall, this yields the supply chain's profit function $J^{S C}: u \mapsto \mathbb{R}$

$J_{T}\left(u ; x_{0}\right):=\int_{0}^{T} \frac{\left(a-c_{M}-c_{0} x(t)^{m}\right)^{2}-r^{2}}{4 b}-c_{S D} u(t) \mathrm{d} t$

for a given time interval $[0, T]$, which must be maximized subject to the control constraints $0 \leq u(t) \leq \omega, t \in[0, T)$, and the system dynamics (3). The contract period $T$ is of particular interest since investments into the cost structure of the supply chain require their amortization during the runtime of the contractual agreement. A summary of the parameters is given in Table 1.

\footnotetext{
${ }^{1}$ Because supplier development is most often used as of the end of the growth stage as opposed to initial stages of a product's life cycle, we consider solely the learning that occurs through the cumulative number of realized supplier development projects without considering further effects, e.g., total number of units produced $[5,30]$.
}

\subsection{Solution of the optimal control problem}

Pontryagin's maximum principle, see, e.g., [26], is used analogously to [20] to solve the optimal control problem introduced in the preceding subsection. To formulate the necessary optimality conditions, we require the so-called Hamiltonian $\mathcal{H}$, which is defined as

$$
H(x, u, \lambda):=\frac{\left(a-c_{M}-c_{0} x^{m}\right)^{2}-r^{2}}{4 b}-c_{S D} u+\lambda u .
$$

From the necessary conditions, we obtain the system dynamics

$$
\dot{x}^{\star}(t)=H_{\lambda}\left(x^{\star}(t), u^{\star}(t), \lambda(t)\right)=u^{\star}(t),
$$

the so-called adjoint $\lambda:[0, T] \rightarrow \mathbb{R}$, which is characterized by

$$
\dot{\lambda}(t)=-H_{x}\left(x^{\star}(t), u^{\star}(t), \lambda(t)\right)=\frac{m c_{0} x^{\star}(t)^{m-1}\left(a-c_{M}-c_{0} x^{\star}(t)^{m}\right)}{2 b},
$$

and the transversality condition

$$
\lambda(T)=0 .
$$

The solution $u^{\star}:[0, T) \rightarrow[0, \omega]$ of the optimal control problem exhibits the structural property

$u^{\star}(t):=\left\{\begin{array}{lll}\omega & \text { if } & t<t^{\star} \\ 0 & \text { if } & t \geq t^{\star}\end{array}\right.$

depending on the (optimal) switching time $t^{\star} \in[0, T]$, which is characterized by the equation

$$
\frac{m c_{0}\left(x_{0}+\omega t^{\star}\right)^{m-1}\left(a-c_{M}-c_{0}\left(x_{0}+\omega t^{\star}\right)^{m}\right)}{2 b}=\frac{c_{S D}}{\left(t^{\star}-T\right)} .
$$

In the following, (9) is called switching condition. Indeed, since the cost function is (strictly) convex and the system dynamics are governed by a linear ordinary differential equation, it can be shown that this condition is necessary and sufficient for the considered problem, see [36] for a detailed derivation. We emphasize that the switching time $t^{\star}$ characterizes the optimal time of collaboration since every investment in supplier development up to $t^{\star}$ results in an increased profit while expenditures spent after $t^{\star}$ do not amortize during the contract period and are, thus, not economically reasonable within the considered setting.

The optimal value function $V_{T}\left(x_{0}\right)$ of the problem under consideration reads

$$
V_{T}\left(x_{0}\right):=\sup _{u \in \mathcal{L}^{\infty}([0, T),[0, \omega])} J_{T}^{S C}\left(u ; x_{0}\right)
$$




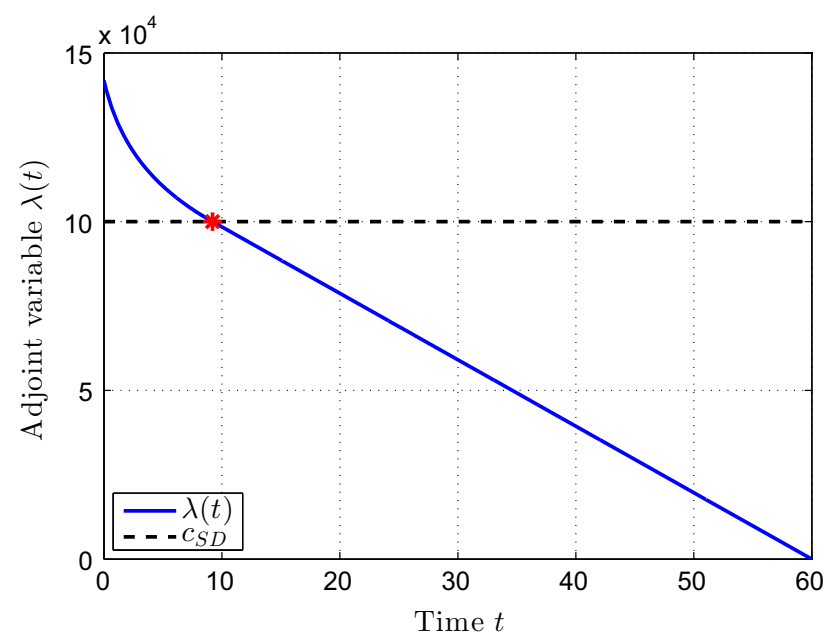

Fig. 1 The adjoint $\lambda:[0, T] \rightarrow \mathbb{R}_{\geq 0}$ computed based on the parameters given in Table 1

where the expression on the right-hand side is maximized subject to $\dot{x}(t)=u(t), x(0)=x_{0} . V_{T}: \mathbb{R}>0 \rightarrow \mathbb{R}$ maps the initial value $x_{0}$ to the optimal value. The index $T$ indicates the contract period and can be considered as a parameteran interpretation, which is crucial for the upcoming analysis.

Evidently, investments (in the cost structure) pay off in the long run: while all the effort is spent directly at the beginning of the collaboration, the resulting cost decreasing effect is exploited during the remainder of the contract period.

Remark 1 At the switching time $t^{\star}$, the marginal revenue of further investments in supplier development (given by the adjoint variable $\lambda$ ) equals the marginal costs (given by $\left.c_{S D}\right)$ as indicated in Fig. 1. This reasoning is expressed by the switching condition (9).

\section{Interplay of switching time and contract period}

If the desired contract between manufacturer $M$ and supplier $S$ ranges over the interval $[0, T]$, two cases can be distinguished:

1. The (optimal) switching time is given by $t^{\star}=0$ meaning that investments in supplier development do not pay off during the contract period.

2. A switching time $t^{\star}>0$ represents the scenario where investing into supplier development amortizes during the contract period.

After determining the outcome of a potential collaboration over the interval $[0, T]$, the overall market situation has to be taken into account, e.g., does it make (more) sense to cooperate with a different supplier instead of adhere to the already existing business relation, see, e.g., [12] and [36] for the considered setting with multiple suppliers. Here, however, it is supposed that continuation of the collaboration is preferable since our focus is on the arrangement of the manufacturer/supplier cooperation. Hence, Option 1 corresponds to the scenario, in which supplier development cannot increase profitability within the supply chain and the cooperation with another supplier acting on the market is also not economically reasonable. Hence, we focus on the second case within this paper.

Here, from the specific structure (8) of the optimal control function we can conclude that all investments up to time $t^{\star}$ pay off during the contract period. Then, taking into account the already reduced supply costs given by $c_{S C}(t)=r+c_{0} x\left(t^{\star}\right)^{m}$ with

$c_{0} x\left(t^{\star}\right)^{m}=c_{0}\left(x_{0}+\int_{0}^{t^{\star}} u^{\star}(s) \mathrm{d} t\right)^{m}=c_{0}\left(1+\omega t^{\star}\right)^{m}$,

further effort in terms of $u(t)>0, t \in\left[t^{\star}, T\right)$, does not lead to an increased profit. The latter holds true since cost-reduction efforts after $t^{\star}$ do not amortize within the remaining time interval of at most length $T-t^{\star}$ and are, thus, not economically reasonable. We show that a prolongation of the contract period yields an augmentation of the investments in supplier development, which corresponds to an increased switching time $t^{\star}$. A proof of Lemma 1 is given in "Appendix 8".

Lemma 1 Suppose that the contract period $T$ is chosen (long enough) such that $t^{\star}=t^{\star}(T)>0$ holds. In addition, let the condition

$(1-m)\left(a-c_{M}-c_{0}\right)+c_{0} m \geq 0$

hold. Then prolonging the contract period $\bar{T}, \bar{T}>T$, implies a strictly larger switching time $t^{\star}=t^{\star}(\bar{T})$, i.e., $t^{\star}(\bar{T})>t^{\star}(T)$.

Remark 2 The assumptions of Lemma 1 imply the inequality $a-c_{M}-c_{0}-r>0$ as a by-product because the manufacturer cannot realize a profit per unit sold otherwise (prohibitive price is greater than the production cost per unit at time $t=0$ from the manufacturer's point of view). Hence, the seemingly technical Condition (10) links the supplier's production costs $c_{0}$ with the difference of profit per unit $a-c_{M}-c_{0}$ by the learning rate $m$. Note that the assumptions of Lemma 1 can be easily verified for a given dataset of parameters.

Lemma 1 shows that investments in supplier development are extended if the contract period is prolonged. Hence, the collaboration continues after the previously determined switching time $t^{\star}$. As a result, the supplier's 
Fig. 2 Optimal switching time $t^{\star}=t^{\star}(\bar{T})$ in dependence of the length of the contract $\bar{T}=$ $T+i \cdot \Delta T(T=60, \Delta T=3$ and $i=0,1, \ldots, 7)$

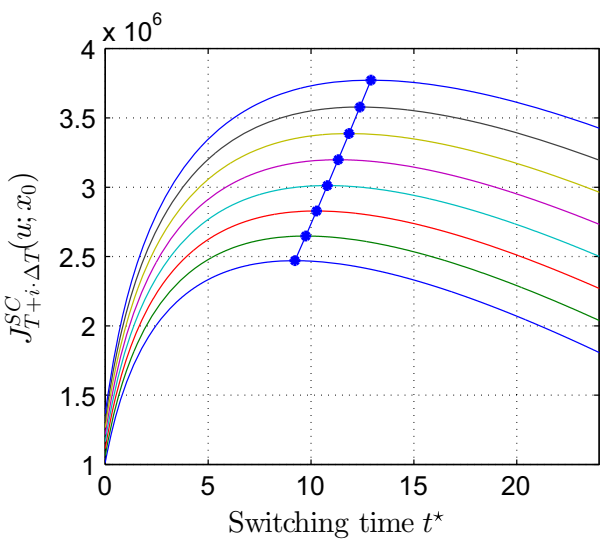

unit production costs are further decreased, the quantity offered is increased and the supply chain profit per time unit grows. The argument that a longer contract period leads to larger switching times can also be validated numerically as visualized in Fig. 2. Here, we observe that the supply costs $c_{S C}(t)=r+c_{0} x(t)^{m}$ are further reduced if both the manufacturer and the supplier agree on a longer contract period. The relation between the contract period $T$ and the optimal switching time $t^{\star}(T)$ is almost linear. ${ }^{2}$

In summary and according to the initial question how does the contract period, i.e., planning horizon, affect firms' willingness to commit relationship-specific resources to supplier development, the findings show that the supply chain partners' incentives to commit relationship-specific resources, i.e., to invest in cost-reduction efforts, critically depend on the length of the contract period.

\section{Successive prolongation of the contract period}

The benefits of an increased switching time come along with the inflexibility resulting from long-term contracts. In this section, we propose a methodology for assisting supply chain partners in contract negotiations to achieve the benefits of long-term contracts while committing themselves only to agreements of a certain, prespecified (collaboration) time period. To this end, it is assumed that the manufacturer and the supplier are only content to make contracts of length $T$. If the collaboration is successful for a certain amount of time $[0, \Delta T), \Delta T \leq t^{\star}$, they might agree to renew the contract on the time interval $[\Delta T, T+\Delta T]$.

Before we continue the discussion, let us briefly sketch the computation of the (optimal) control function $u^{\star}:[\Delta T, T+\Delta T) \rightarrow[0, \omega]$. Here, the profit function has to be maximized based on the new (initial) state $x(\Delta T)$,

\footnotetext{
${ }^{2}$ Indeed, the slope of the curve is slightly increasing.
}

i.e., $J_{T}^{S C}(\cdot ; x(\Delta T))$ is considered. Since $\Delta T \leq t^{\star}$ holds by assumption, the new initial state $x(\Delta T)$ is given by

$x(\Delta T)=x(0)+\int_{0}^{\Delta T} u^{\star}(s) \mathrm{d} t=x_{0}+\Delta T \cdot \omega$

in view of Property (8). Hence, the profit on the new contract period $[\Delta T, T+\Delta T]$ is determined by maximizing

$J_{T}(u ; x(\Delta T))=\int_{0}^{T} \frac{\left(a-c_{M}-c_{0} \tilde{x}(t)^{m}\right)^{2}-r^{2}}{4 b}-c_{S D} u(t) \mathrm{d} t$

subject to $u(t) \in[0, \omega], t \in[0, T)$ and the differential equation (3) with initial condition $\tilde{x}(0)=x(\Delta T)=$ $x_{0}+\omega \Delta T$. Here, we used the notation $\tilde{x}$ to distinguish the previously computed (state) trajectory $x\left(\cdot ; x_{0}\right)$ and its counterpart $\tilde{x}(\cdot ; x(\Delta T))$ depending on the new initial condition $x(\Delta T)$. Another option is to use the time invariance of the linear differential equation $\dot{x}(t)=u(t)$, which allows to rewrite the profit functional as

$$
\int_{\Delta T}^{T+\Delta T} \frac{\left(a-c_{M}-c_{0} x(t)^{m}\right)^{2}-r^{2}}{4 b}-c_{S D} u(t) \mathrm{d} t
$$

with initial value $x(\Delta T)$ given by (11) at initial time $\Delta T$. We point out that the resulting trajectory deviates from the previously computed one already before time $T$. In conclusion, the implemented control strategy on $[0, T+\Delta T)$ is given by

$$
u(t):=\left\{\begin{array}{ll}
u^{\star}(t) \text { maximizing } J_{T}^{S C}\left(\cdot ; x_{0}\right) & t \in[0, \Delta T) \\
u^{\star}(t) \text { maximizing } J_{T}^{S C}(\cdot ; x(\Delta T)) & t \geq \Delta T
\end{array},\right.
$$

i.e., the first piece of the old policy concatenated with the newly negotiated strategy. This strategy yields an optimal policy on the time span $[0, T+\Delta T)$. Hence, the same overall supply chain profit is reached without the hazards of being committed already at the beginning (time 0 ) as shown in the following corollary. 
Corollary 1 Let the optimal switching time $t^{\star}$ determined by Condition (9) be strictly greater than zero. Furthermore, let $\Delta T, \Delta T<t^{\star}$, be given. Then, the control strategy defined in (12) and the corresponding supply chain profit on $[0, T+\Delta T]$ equal their counterparts obtained by maximizing $J_{T+\Delta T}\left(u ; x_{0}\right)$ with respect to $u:[0, T+\Delta T) \rightarrow[0, \omega]$

Proof Since the profit $J_{T+\Delta T}\left(u ; x_{0}\right)$ on the considered time interval $[0, T+\Delta T]$ with $u$ from (12) is the sum of

$\int_{0}^{\Delta T} \frac{\left(a-c_{M}-c_{0} x(t)^{m}\right)^{2}-r^{2}}{4 b}-c_{S D} \omega \mathrm{d} t$

and

$$
+\int_{\Delta T}^{T+\Delta T} \frac{\left(a-c_{M}-c_{0} x(t)^{m}\right)^{2}-r^{2}}{4 b}-c_{S D} u(t) \mathrm{d} t,
$$

the dynamic programming principle yields the equality

$J_{T+\Delta T}\left(u ; x_{0}\right)=V_{T+\Delta T}\left(x_{0}\right)$,

which completes the proof.

\subsection{Receding horizon control}

The idea of an iterative prolongation of collaboration contracts can be algorithmically formalized as receding horizon control (RHC) also known as model predictive control.

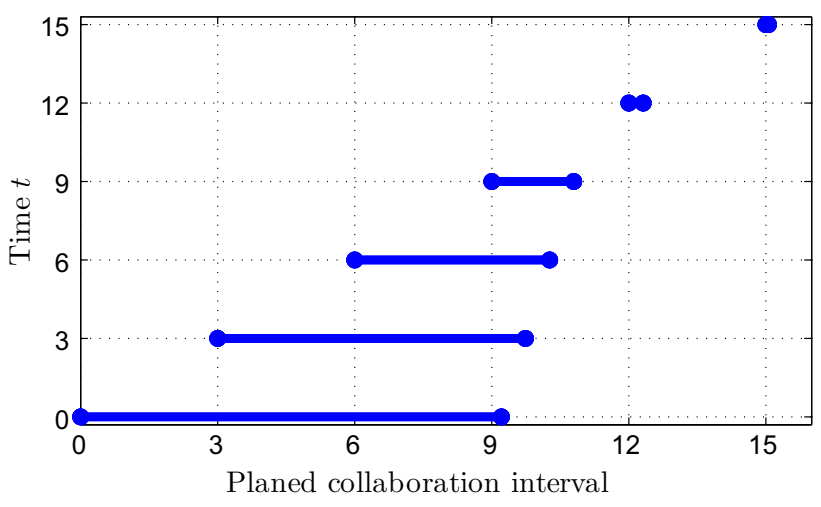

Fig. 3 Application of Algorithm 1 to compute the optimal switching times for $T=60$ and changing initial conditions $\hat{x}$. The lengths of the collaboration intervals are decreasing

previously described steps are repeated, which is referred to as receding horizon principle. Note that since the underlying system dynamics are time invariant, the newly (measured) initial state $\hat{x}$ represents all information required. In particular, no knowledge regarding the previously applied control is needed to solve the adapted switching condition of Step (2) with respect to $t^{\star}$. Figure 3 illustrates the outcome of Algorithm 1 with prediction horizon $T=60$ (contract period) and control horizon $\Delta T=3$ (time step) based on the parameters given in Table 1.

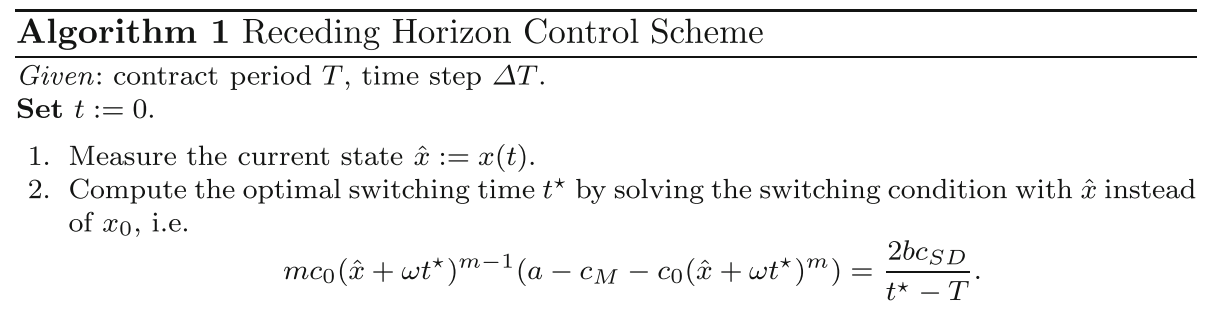

3. Set

$$
u^{\star}(s):= \begin{cases}\omega & \text { for } t \leq s<\min \left\{t+t^{\star}, t+\Delta T\right\} \\ 0 & \text { for } \min \left\{t+\Delta T, t+t^{\star}\right\} \leq s \leq t+\Delta T\end{cases}
$$

4. Apply $u^{\star}(s)$ for $s \in[t, t+\Delta T)$. Set $t=t+\Delta T$ and go to Step (1).

Upon start, the manufacturer $M$ and the supplier $S$ agree on a collaboration for a given contract period of length $T$. Firstly, the status quo-represented by $\hat{x}$-is analysed. Secondly, the optimal switching time $t^{\star}$ is computed based on the initial state $\hat{x}$ and $T$, cf. Step (2). This yields the optimal control strategy defined by (13), of which the first piece $\left.u^{\star}\right|_{[0, \Delta T)}$ is applied. Then, the manufacturer and the supplier meet again at time $t+\Delta T$ to negotiate a new contract. This initiates the process again, i.e.. the
Firstly $(t=0)$, the original optimal control problem is solved resulting in $t^{\star} \approx 9.21$. Then, $u^{\star} \equiv \omega$ is applied on the time interval $[0, \Delta T)$. Secondly $(t=\Delta T)$, the collaboration is prolonged to $t^{\star} \approx 9.74$. Thirdly $(t=2 \Delta T)$, the switching time is shifted to $t^{\star} \approx 10.27$. Still, $t=3 \Delta T \leq t^{\star}$ holds. Hence, the (measured) initial state $\hat{x}$ is given by $x_{0}+t \omega=x_{0}+3 \Delta T \omega$. Here, Step (2) of Algorithm (1) yields $t^{\star} \approx 10.79$, i.e., the collaboration stops within the time frame $[t, t+\Delta T)$. If the RHC scheme is further 
applied, there occur collaboration intervals of shrinking length.

As already discussed in Sect. 5, if the contract is not renewed, $u^{\star}(t)$ is set to zero for $t \geq t^{\star} \approx 9.21$. In contrast to that, the RHC scheme prolongs the collaboration and, thus, increases the supply chain profit. To be more precise, the profit generated by Algorithm 1 on $[0, T+i \Delta T]$, $i \in\{0,1,2, \ldots, T / \Delta T\}$,

$$
\sum_{k=0}^{T / \Delta T+i-1} \int_{k \Delta T}^{(k+1) \Delta T} \frac{\left(a-c_{M}-c_{0} x(t)^{m}\right)^{2}-r^{2}}{4 b}-c_{S D} u(t) \mathrm{d} t
$$

is greater than its counterpart $J_{T}\left(u^{\star}, x_{0}\right)+V_{i \Delta T}\left(x^{\star}(T)\right)$ consisting of the maximum of the original cost function $V_{T}\left(x_{0}\right)=J_{T}\left(u^{\star}, x_{0}\right)$ and a second (optimally operated) contract on $[T, T+i \Delta T]$ based on the reached cost structure represented by $x^{\star}(T)=x_{0}+t^{\star} \omega \approx x_{0}+$ $9.21 \omega=10.21$. In particular, this assertion holds in comparison with simply sticking to the cost structure based on $t^{\star}(T)$, i.e.,

$J_{T}\left(u^{\star}, x_{0}\right)+\int_{T}^{T+i \Delta T} \frac{\left(a-c_{M}-c_{0} x\left(t^{\star}(T)\right)^{m}\right)^{2}-r^{2}}{4 b} \mathrm{~d} t$.

While an increased switching time $t^{\star}$ may already increase the profitability within a supply chain during the considered time span, the achieved cost reduction sustains. Hence, if the collaboration between the manufacturer and the supplier lasts, the obtained effect is a sustainable one.

In summary and referring to the question how does receding horizon control offer a straightforward method for dynamically extending the planning horizon, the findings show that dynamically extending contracts enhance the supplier development process, because value generation is facilitated while both the manufacturer and the supplier gain flexibility due to shorter contract periods.

\subsection{Optimal point of collaboration}

As observed in Fig. 3, the collaboration can stop within the time interval $[t, t+\Delta T)$ meaning that the prerequisite $\Delta T \leq t^{\star}$ is no longer satisfied at time $t$. This leads to a sequence of collaboration times of shrinking length. Summing up all of these intervals on the infinite horizon yields a total collaboration time of approximately 11.18 time units. Hence, the total collaboration time is increased by $21.3 \%$. However, since the collaboration intervals are becoming comparably short, implementing this strategy may be impracticable. Here, we propose two remedies: If the new collaboration period at time $t=k \Delta T$, i.e., $t^{\star}-t$, is below a certain threshold value,
1. set $t^{\star}=t$ in order to save negotiation costs, which would probably outweigh the achievable earning growth. For the presented example, the supplier development programme stops at 10.79 (still an increase of approximately $17.2 \%$ ) if the threshold is 1 .

2. measure the current state $\hat{x}=x(t)$ and compute the optimal cost structure for contract periods of length $T$ by solving

$m c_{0} T \bar{x}^{m-1}\left(a-c_{M}-c_{0} \bar{x}^{m}\right)+2 b c_{S D}=0$

with respect to $\bar{x}$. Then, set $t^{\star}=t+(\bar{x}-\hat{x}) / \omega$. In the considered example at time $t=4 \Delta T$, the measured state is $\hat{x}=10.79$ while $\bar{x} \approx 11.18$. Hence, a collaboration of length 0.39 time units is fixed. At all upcoming time instants, $t^{\star}=t$ holds because the optimal cost structure for contract periods of length $T=60$ is already reached.

Clearly, the threshold should be chosen such that the profit increase outweighs the negotiation costs.

Thus, Algorithm 1 allows both the manufacturer and the supplier to prolong their supplier development programme without binding themselves for a time span longer than $T$ and, thus, provides more flexibility.

Remark 3 Algorithm 1 is a simplified version. Indeed, the time step $\Delta T$ may vary in time, e.g., longer time steps in the beginning (for example, $\Delta T=t^{\star}$ in the considered setting), and shorter ones later on. For details on the socalled time-varying control horizon, we refer to [15].

In summary and with regard to the question how should receding horizon control be arranged to optimize supply chain profit, two strategies are presented in order to make the proposed receding horizon scheme, cf. Algorithm 1, applicable even if negotiation costs are taken into account.

\section{Numerical results}

As seen in the previous section, applying the receding horizon Algorithm 1 dynamically extends the collaboration within the supply chain and, thus, generates additional profit within the supply chain. Next, we conduct a numerical case study to obtain further managerial insights.

To this end, we compare the outcome $J^{\star \star}$ of the proposed algorithm based on the second option presented in Sect. 5.2 and the supply chain profit resulting from the control

$u(t)= \begin{cases}\omega & \text { for } \quad t<t^{\star}(T) \\ 0 & \text { for } t \geq t^{\star}(T)\end{cases}$

on the time interval $[0,2 T]=[0,120]$. The control policy (15) results from the basic optimal control problem 
considered on $[0,60]$ and, then, utilizing the achieved cost structure $c_{S C}(t)=x_{0}+t^{\star} \omega$ on $[60,120]$ without further investments in supplier development. The corresponding profit is given by (14).

To fully understand the impact of receding horizon control on the supply chain profit in depth, we first vary the following parameters of Table 1

$$
\begin{aligned}
a & \in\{192.5,195,197.5,200,202.5,205,207.5\}, \\
b & \in\{0.007,0.008,0.009,0.01,0.011,0.012,0.013\}, \\
c_{S D} & \in\{70000,80000,90000,100000,110000,120000,130000\}, \\
\omega & \in\{0.7,0.8,0.9,1,1.1,1.2,1.3\}, \\
m & \in\{-0.13,-0.12,-0.11,-0.1,-0.09,-0.08,-0.07\}
\end{aligned}
$$

resulting in a total number of $7^{5}=16,807$ instances. For each parameter combination, we then evaluate the respective profits.

The depicted histogram in Fig. 4 shows the absolute frequency with which a percentage of profit increase is observed within our parameter set. The mean value is $3.36 \%$ with a standard deviation of $1.06 \%$. In conclusion, receding horizon control significantly improves the profitability of the considered supply chain.

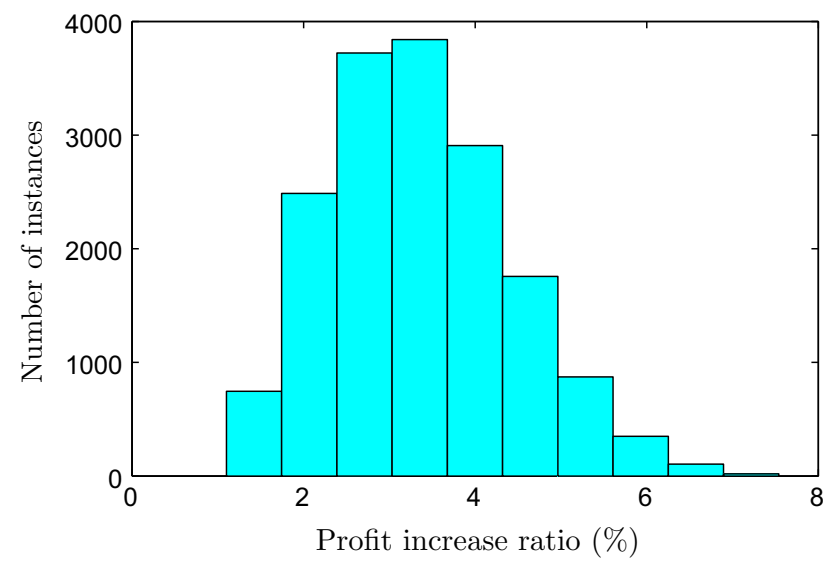

Fig. 4 Profit increase ratio in percent
Second, we are interested in the interplay of the supplier's learning rate $m$ and receding horizon control. Thus, based on the parameters of Table 1, we perform a sensitivity analysis with respect to the parameter $m$ with

$$
\begin{aligned}
m \in\{ & -0.15,-0.14,-0.13,-0.12,-0.11, \\
& -0.1,-0.09,-0.08,-0.07,-0.06,-0.05\} .
\end{aligned}
$$

Applying Algorithm $1(T=60, \Delta T=3)$, Fig. 5 shows both the optimal switching time $t^{\star}$ (without receding horizon control) compared to the optimal switching time $t^{\star \star}$ (with receding horizon control) in dependence of $m$ (left), and the profit growth with respect to the switching time for different learning rates (right). Again, the computations are based on a simulation of 120 time units. Here, we observe that the impact of receding horizon control decreases for lower learning rates.

Hence, the results infer that especially firms in highlearning industries, e.g., technology-based industries, benefit most from applying the proposed receding horizon scheme.

\section{Conclusion}

In this paper, we investigated the impact of the contract period on supplier development. In particular, we showed that the supply chain partners' incentives to commit relationship-specific resources, i.e., to invest in cost-reduction efforts, critically depend on the length of the contract period.

Given the fact that long-term contracts entail certain risks, we proposed a receding horizon control scheme to mitigate possible contractual hazards. In addition, we showed that dynamically extending contracts enhance the supplier development process, because value generation is facilitated while both the manufacturer and the supplier gain flexibility due to shorter contract periods. Furthermore, we presented two strategies in order to make the
Fig. 5 Optimal switching time $t^{\star}$ and $t^{\star \star}$ with respect to the parameter $m$ (left) and earning growth with respect to the switching time $t^{\star}$ for different values of $m$ (right)
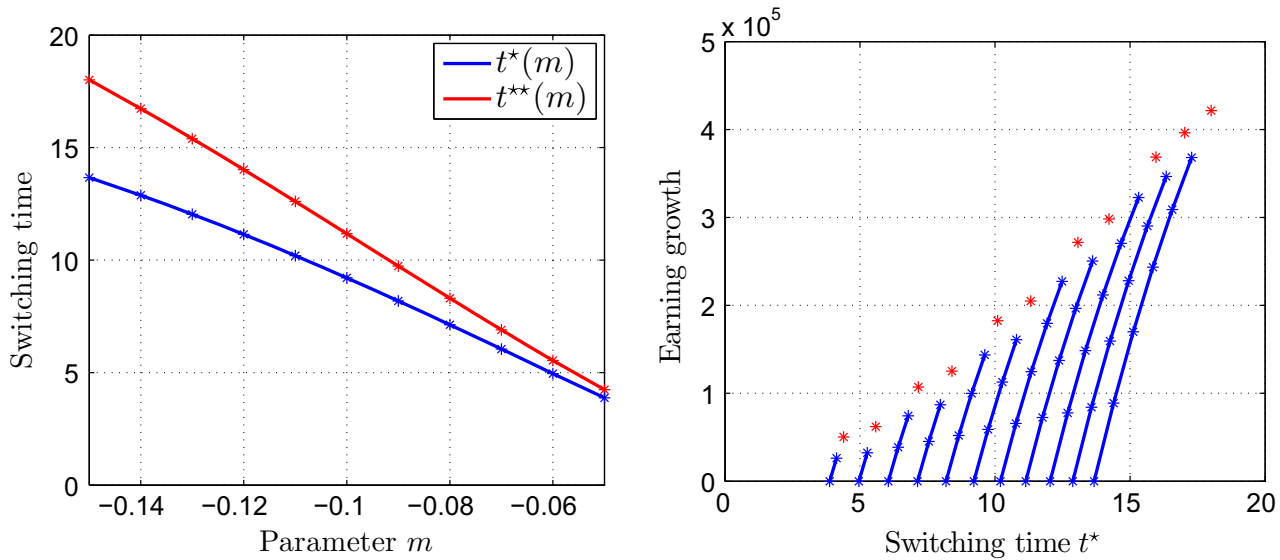
proposed receding horizon scheme, cf. Algorithm 1, applicable even if negotiation costs are taken into account.

Finally, we verified the reliability of the application by performing Algorithm 1 for an extensive parameter set and demonstrated that receding horizon control leads to a significant profit increase within the supply chain. Moreover, by means of a sensitivity analysis with respect to the learning rate, we showed that especially firms in highlearning industries benefit since supplier development programmes play a predominant role in order to optimize the cost structure of the supplier network.

The study is based on a simple model to focus on the impact of dynamical decision-making in supplier development. Clearly, a more elaborated model with less stringent assumptions like, e.g., a linear price distribution, should be studied in the future. Moreover, the combination of the proposed dynamic strategy with decentralized approaches is of great importance and deserved a detailed analysis, see, e.g., the negotiation-based coordination mechanism proposed in [36]. Another interesting direction for future research is to expand our study to a network perspective, in which the supply chain consists of more than a single manufacturer and a single supplier, see, e.g., [13], where two manufacturers are engaged in the development of a supplier.

Open Access This article is distributed under the terms of the Creative Commons Attribution 4.0 International License (http://crea tivecommons.org/licenses/by/4.0/), which permits unrestricted use, distribution, and reproduction in any medium, provided you give appropriate credit to the original author(s) and the source, provide a link to the Creative Commons license, and indicate if changes were made.

\section{A proof of Lemma 1}

In this section, a proof of Lemma 1 about the interplay of the contract period $T$ and the optimal switching time $t^{\star}$ is given.

Proof Let the monotonic function $z: t^{\star} \mapsto 1+\omega t^{\star}$ be defined, which maps the switching time $t^{\star}$ to the state $x\left(t^{\star}\right)$ at the switching time $t^{\star}$. Furthermore, note that $z^{\prime}\left(t^{\star}\right)=\omega$ holds. Then, the switching condition (9) can be rewritten as

$$
\left(T-t^{\star}\right) z\left(t^{\star}\right)^{m-1}\left(a-c_{M}-c_{0} z\left(t^{\star}\right)^{m}\right)=\frac{-2 b c_{S D}}{m c_{0}} .
$$

Clearly, the left- and the right-hand sides are positive $(m<0)$. While the right-hand side is independent of both $T$ and $t^{\star}$, the left-hand side can be interpreted as a function of the switching time $t^{\star}$ for a given contract period $T$. Let $f:[0, T] \rightarrow \mathbb{R}_{\geq 0}$ be defined by
$f\left(t^{\star}\right):=\left(T-t^{\star}\right) z\left(t^{\star}\right)^{m-1}\left(a-c_{M}-c_{0} z\left(t^{\star}\right)^{m}\right)$.

Then, the term $-f^{\prime}\left(t^{\star}\right) \cdot z\left(t^{\star}\right)^{m-2}$ is a sum consisting of the positive summand $z\left(t^{\star}\right)\left(a-c_{M}-c_{0} z\left(t^{\star}\right)^{m}\right)$ and

$\left(T-t^{\star}\right) \omega \cdot\left((1-m)\left(a-c_{M}-c_{0} z\left(t^{\star}\right)^{m}\right)+c_{0} m z\left(t^{\star}\right)^{m}\right)$.

Here, it was used that $a-c_{M}-c_{0}-r>0$ holds. Hence, we investigate the term

$$
(1-m)\left(a-c_{M}-c_{0} z\left(t^{\star}\right)^{m}\right)+c_{0} m z\left(t^{\star}\right)^{m}
$$

in order to determine the sign of the second summand using that $\left(T-t^{\star}\right) \omega>0$ holds. To this end, the supply chain profit $p:=a-c_{M}-c_{0}>r>0$ per unit plays a major role: (17) equals

$$
c_{0} \cdot\left((1-m) p / c_{0}+m z\left(t^{\star}\right)^{m}\right)+\underbrace{(1-m)\left(c_{0}-c_{0} z\left(t^{\star}\right)^{m}\right)}_{\geq 0}
$$

because $m<0$ and $t^{\star} \geq 0$ hold. Positivity of the first summand is ensued from (10). Hence, (17) is positive and, thus, $f^{\prime}$ is (strictly) decreasing.

In conclusion, the left-hand side of (16) is strictly decreasing in $t^{\star}$ and strictly increasing in $T$. As a consequence, using $\bar{T}, \bar{T}>T$, instead of $T$, i.e., considering the optimal control problem on a longer time horizon (contract period), leads a larger switching time $t^{\star}$ in order to ensure validity of the switching condition (9).

\section{References}

1. Artz KW (1999) Buyer-supplier performance: the role of asset specificity, reciprocal investments and relational exchange. Br J Manag 10(2):113-126

2. Aulakh PS, Gençtürk FE (2014) Contract formalization and governance of exporter-importer relationships. J Manage Stud 45(3):457-479

3. Bai C, Sarkis J (2014) Supplier development investment strategies: a game theoretic evaluation. Ann Oper Res 240(2):583-615

4. Bernstein F, Kök AG (2009) Dynamic cost reduction through process improvement in assembly networks. Manage Sci 55(4):552-567

5. Birou L, Fawcett SE, Magnan GM (1997) Integrating product life cycle and purchasing strategies. Int $\mathbf{J}$ Purch Mater Manag 33(4):23-31

6. Boccia A, Grüne L, Worthmann K (2014) Stability and feasibility of state constrained MPC without stabilizing terminal constraints. Syst Control Lett 72:14-21

7. Carson SJ, Madhok A, Wu T (2006) Uncertainty, opportunism, and governance: the effects of volatility and ambiguity on formal and relational contracting. Acad Manag J 49(5):1058-1077

8. Dyer JH (1996a) Specialized supplier networks as a source of competetive advantage: evidence drom the auto industry. Strateg Manag J 17(4):271-291

9. Dyer JH (1996b) Does governance matter? Keiretsu alliances and asset specificity as sources of Japanese competitive advantage. Organ Sci 7(6):649-666 
10. Dyer JH, Singh H (1998) The relational view: cooperative strategy and sources of interorganizational competitive advantage. Acad Manag Rev 23(4):660-679

11. Fine CH, Porteus EL (1989) Dynamic process improvement. Oper Res 37(4):580-591

12. Friedl G, Wagner SM (2012) Supplier development or supplier switching? Int J Prod Res 50(11):3066-3079

13. Friedl G, Wagner SM (2016) Supplier development investments in a triadic setting. IEEE Trans Eng Manage 63(2):136-150

14. Grüne L, Pannek J (2011) Nonlinear model predictive control. Springer, London

15. Grüne L, Pannek J, Seehafer M, Worthmann K (2010) Analysis of unconstrained nonlinear MPC schemes with time-varying control horizon. SIAM J Control Optim 48(8):4938-4962

16. Grüne L, Semmler W, Stieler M (2015) Using nonlinear model predictive control for dynamic decision problems in economics. J Econ Dyn Control 60:112-133

17. Humphreys P, Cadden T, Wen-Li L, McHugh M (2011) An investigation into supplier development activities and their influence on performance in the Chinese electronics industry. Prod Plan Control 22(2):137-156

18. Ivanov D, Dolgui A, Sokolov B (2012) Applicability of optimal control theory to adaptive supply chain planning and scheduling. Ann Rev Control 36(1):73-84

19. Ivanov D, Sokolov B (2013) Control and system-theoretic identification of the supply chain dynamics domain for planning, analysis and adaptation of performance under uncertainty. Eur $\mathbf{J}$ Oper Res 224(2):313-323

20. Kim B (2000) Coordinating an innovation in supply chain management. Eur J Oper Res 123(3):568-584

21. Kim S-H, Netessine S (2013) Collaborative cost reduction and component procurement under information asymmetry. Manage Sci 59(1):189-206

22. Krause DR (1999) The antecedents of buying firms' efforts to improve suppliers. J Oper Manag 17(2):205-224

23. Krause DR, Ellram LM (1997) Success factors in supplier development. Int J Phys Distri Logisti Manag 27(1):39-52

24. Krause DR, Scannell TV (2002) Supplier development practices: product- and service-based industry comparisons. J Supply Chain Manag 38(1):13-21

25. Krause DR, Handfield RB, Tyler BB (2007) The relationships between supplier development, commitment, social capital accumulation and performance improvement. J Oper Manag 25(2):528-545

26. Lee EB, Marcus L (1967) Foundations of optimal control theory. Wiley, New York

27. Li H, Wang Y, Yin R, Kull TJ, Choi TY (2012) Target pricing: demand-side versus supply-side approaches. Int $\mathrm{J}$ Prod Econ 136(1):172-184

28. Li W, Humphreys PK, Yeung AC, Cheng TE (2007) The impact of specific supplier development efforts on buyer competitive advantage: an empirical model. Int J Prod Econ 106(1):230-247

29. Liker JK, Choi TV (2002) Building deep supplier relationships. Harvard Bus Rev 82(12):104-113

30. Mahapatra SK, Das A, Narasimhan R (2012) A contingent theory of supplier management initiatives: effects of competitive intensity and product life cycle. J Oper Manag 30(5):406-422

31. Pannek J, Worthmann K (2014) Stability and performance guarantees for model predictive control algorithms without terminal constraints. ZAMM J Appl Math Mech Special Issue Control Theory Digit Netw Dyn Syst 94(4):317-330

32. Pannocchia G, Rawlings JB, Wright SJ (2011) Conditions under which suboptimal nonlinear MPC is inherently robust. Syst Control Lett 60(9):747-755
33. Perea-Lopez E, Ydstie BE, Grossmann IE (2003) A model predictive control strategy for supply chain optimization. Comput Chem Eng 27(8):1201-1218

34. Praxmarer-Carus S, Sucky E, Durst SM (2013) The relationship between the perceived shares of costs and earnings in supplier development programs and supplier satisfaction. Ind Mark Manage 42(2):202-210

35. Poppo L, Zenger T (2002) Do formal contracts and relational governance function as substitutes or complements? Strateg Manag J 23(8):707-725

36. Proch M, Worthmann K, Schlüchtermann J (2016) A negotiationbased algorithm to coordinate supplier development in decentralized supply chains. Eur J Oper Res. doi:10.1016/j.ejor.2016. 06.029

37. Rokkan AI, Heide JB, Wathne KH (2003) Specific investments in marketing relationships: expropriation and bonding effects. J Mark Res 40(2):210-224

38. Routroy S, Pradhan SK (2013) Evaluating the critical success factors of supplier development: a case study. Benchmark Int $\mathbf{J}$ 20(3):322-341

39. Sako M (2004) Supplier development at Honda, Nissan and Toyota: comparative case studies of organizational capability enhancement. Ind Corp Change 13(2):281-308

40. Sánchez-Rodríguez C (2009) Effect of strategic purchasing on supplier development and performance: a structural model. J Bus Ind Market 24(3/4):161-172

41. Sánchez-Rodríguez C, Hemsworth D, Martínez-Lorente AR (2005) The effect of supplier development initiatives on purchasing performance: a structural model. Supply Chain Manag Int J 10(4):289-301

42. Schepker DJ, Oh WY, Martynov A, Poppo L (2014) The many futures of contracts moving beyond structure and safeguarding to coordination and adaptation. J Manag 40(1):193-225

43. Sethi S, Sorger G (1991) A theory of rolling horizon decision making. Ann Oper Res 29(1):387-415

44. Talluri S, Narasimhan R, Chung W (2010) Manufacturer cooperation in supplier development under risk. Eur J Oper Res 207(1):165-173

45. Telser LG (1980) A theory of self-enforcing agreements. J Bus 53(1):27-44

46. Vásquez R, Iglesías V, Rodriguez-del Bosque I (2007) The efficacy of alternative mechanisms in safeguarding specific investments from opportunism. J Bus Ind Market 22(7):498-507

47. Wagner SM (2006) A firm's responses to deficient suppliers and competitive advantage. J Bus Res 59(6):686-695

48. Wagner SM (2010) Indirect and direct supplier development: performance implications of individual and combined effects. IEEE Trans Eng Manage 57(4):536-546

49. Wagner SM (2011) Supplier development and the relationship life-cycle. Int J Prod Econ 129(2):277-283

50. Wagner SM, Krause DR (2009) Supplier development: communication approaches, activities and goals. Int $\mathrm{J}$ Prod Res 47(12):3161-3177

51. Wang Q, Li JJ, Ross WT, Craighead CW (2013) The interplay of drivers and deterrents of opportunism in buyer-supplier relationships. J Acad Mark Sci 41(1):111-131

52. Wang W, Rivera DE (2008) Model predictive control for tactical decision-making in semiconductor manufacturing supply chain management. IEEE Trans Control Syst Technol 16(5):841-855

53. Weber L, Mayer KJ, Macher JT (2011) An analysis of extendibility and early termination provisions: the importance of framing duration safeguards. Acad Manag J 54(1):182-202

54. Williamson OE (1979) Transaction-cost economics: the governance of contractual relations. J Law Econ 22(2):233-261 
55. Worthmann K, Braun P, Proch M, Schlüchtermann J, Pannek J (2016) On contractual periods in supplier development. IFACPapers OnLine 49(2):60-65

56. Yelle LE (1979) The learning curve: historical review and comprehensive survey. Decis Sci 10(2):302-328
57. Yu S, Reble M, Chen H, Allgöwer F (2014) Inherent robustness properties of quasi-infinite horizon nonlinear model predictive control. Automatica 50(9):2269-2280 